\section{Dynamic of Campylobacter species contamination along a poultry slaughtering chain}

\author{
Elham Hajj Semaan, ${ }^{1}$ Hussein Dib, ${ }^{2}$ \\ Rachelle Mrad, ${ }^{2}$ Christelle Chami, ${ }^{1}$ \\ Rita Jalkh²
}

'Department of Animal Science and Technology, Lebanese University, Beirut; 2Department of Food Science and Technology, Lebanese University, Beirut, Lebanon

\section{Abstract}

The prevalence of Campylobacters was studied in a poultry farm and along the slaughtering chain. Fifteen swabs from a farm and 75 samples (swabs and rinsates) from its slaughterhouse were collected. All the faecal and cloacal farm swabs were contaminated by Campylobacter jejuni and $C$. coli against 50\% for breast swabs. $C$. jejuni had a concentration of 6.26, 6.34 and $5.38 \log _{10} \mathrm{CFU} / \mathrm{mL}$ in faecal, cloacal and breast swabs respectively. Rinsates showed an almost constant concentration of Campylobacters (6 $\log _{10} \mathrm{CFU} / \mathrm{mL}$ ) with a predominance of the presumptive $C$. jejuni. $C$. lari was found in $22 \%$ of eviscerated samples. Faecal coliforms and E. coli, used as indicators, were detected in all samples (5.46 and $5.15 \log _{10} \mathrm{CFU} / \mathrm{mL}$, respectively). Final chilling and chlorine $(50 \mathrm{ppm})$ treatments decreased them to acceptable levels, unlike for Campylobacters. Further investigation of the dynamics of Campylobacters and their response to prevention and treatment measures is required.

\section{Introduction}

In the European Union Summary Report, undercooked chicken meat was estimated to cause 220,209 cases of confirmed campylobacteriosis in 2011 (EFSA, 2013). Ninety percent of these were caused by Campylobacter jejuni and $5-10 \%$ by $C$. coli (Tam et al., 2003). Despite an earlier description, it was not until 2011 that the United States Department of Agriculture (USDA) set the levels (WattAgNet, 2011). This may explain the absence of standards in Lebanon, where broiler production aims to meet international standards. Research work on Campylobacter human infections is very limited in Lebanon. However, Talhouk et al. (1998) reported rare contaminations in hospitalised humans, whereas Dabboussi et al. (2012) found 11\% of
Campylobacter cases in sick children.

In slaughterhouses, preventive measures are focusing on Salmonella and faecal coliforms. Yet, $75.8 \%$ of broiler carcasses were contaminated by Campylobacters (EFSA, 2011). Contamination may occur through the contact of faecal matter in overcrowded means of transport of animals. Campylobacter-negative batches are contaminated by the surface of equipments (Kudirkiene et al., 2010), while defeathering and evisceration are critical phases (Hue et al., 2010). The objective of this work was to assess the contamination of domestic broilers by Campylobacters at the farm level and throughout the slaughtering operations.

\section{Materials and Methods}

\section{Sampling}

Samples were collected from an open system farm and its slaughterhouse $(12,000$ birds/night) in one single sampling batch from a homogeneous flock. From 5 birds, cotton swabs $\left(5 \times 5 \mathrm{~cm}^{2}\right)$ were taken in duplicates from the breast (BS), cloacae (CS) and fresh faeces (FS). The sampling at the slaughterhouse is presented in Figure 1. Rinsates were obtained by shaking the whole carcasses in peptone water $(0.1 \%)$ for $1 \mathrm{~min}$ in a sterile bag.

\section{Microbiological analysis}

Campylobacter was detected according to ISO 10272-1:2006 (ISO, 2006a). Swabs and rinsates $(1 \mathrm{~mL})$ were first enriched with Bolton Selective Enrichment Broth (CM0983+SR0183 E; Oxoid Ltd., Basingstoke, UK) and 5\% lysed horse blood (SR048; 0xoid Ltd.). The incubation was carried in a microaerobic environment $\left(85 \% \mathrm{~N}, 10 \% \mathrm{CO}_{2}, 5 \% \mathrm{O}_{2}\right)$ for $48 \mathrm{~h}$ at $42^{\circ} \mathrm{C}$ ( $\mathrm{CO}_{2}$ water-jacketed Incubator). Following enrichment, $20 \mu \mathrm{L}$ of diluted swab/rinsate were seeded on mCCDA-Preston (CM0739+ SR0155E; Oxoid Ltd.). Campylobacter spp. was identified by testing for oxidase, catalase, indoxyl acetate hydrolysis and hippurate (Hendriksen et al., 2003). C. jejuni (ATCC 33291; Microbiologics, St. Cloud, MN, USA) served as a positive control. In parallel, rinsates and swabs were tested for aerobic plate count (APC) (ISO 4833:2003; ISO; 2003), faecal coliforms (ISO 4832:2006; ISO, 2006b) and E. coli (ISO 9308-1:2000; ISO, 2000).

\section{Results and Discussion}

\section{Farm level}

Aerobic plate count reached a maximum of $5.71 \log _{10} \mathrm{CFU} / \mathrm{mL}$ in the $\mathrm{CS}$, but scored a lower value (4.71 $\left.\log _{10} \mathrm{CFU} / \mathrm{mL}\right)$ in the $\mathrm{FS}$. Campylobacter concentrations were higher
Correspondence: Elham Hajj Semaan, Department of Animal Science and Technology, Lebanese University, Dekwaneh Road, 20383054 Beirut, Lebanon.

Tel. +961.370 .2419 - Fax: +961.149 .6797$

E-mail: ehajj@ul.edu.lb; elhamhajj@hotmail.com

Key words: Poultry, Microbiology, Campylobacter, Food safety.

Acknowledgments: authors gratefully acknowledge the financial assistance of Lebanese National Council for Scientific Research, Beirut, and the cooperation of Lebanese Poultry Company (LPC), Bauchrieh, Lebanon.

Received for publication: 24 January 2014.

Revision received: 22 May 2014.

Accepted for publication: 27 May 2014.

This work is licensed under a Creative Commons Attribution 3.0 License (by-nc 3.0).

(C) Copyright E.Hajj Semaan et al., 2014

Licensee PAGEPress, Italy

Italian Journal of Food Safety 2014; 3:2246

doi:10.4081/ijfs.2014.2246

with $6.26 \log _{10} \mathrm{CFU} / \mathrm{mL}$ in FS, $6.34 \log _{10}$ $\mathrm{CFU} / \mathrm{mL}$ in $\mathrm{CS}$ and $5.38 \mathrm{Log}_{10} \mathrm{CFU} / \mathrm{mL}$ in BS. Cross-contamination among broilers may have caused the detection of Campylobacter species in $100 \%$ of $\mathrm{FS}$ and $\mathrm{CS}$ against $50 \%$ in BS. The greatest prevalence of Campylobacter jejuni was observed in FS (37.5\%) followed by CS (25\%), then by BS (16.67\%). C. coli were present in $25 \%$ of $\mathrm{CS}, 16.67 \%$ of BS and $12.5 \%$ of FS. Predominance of $C$. jejuni meets previous results obtained by Newell and Fearnley (2003), but disagrees with those from Greek farms contaminated only with $C$. coli (Marinou et al., 2012). Unidentified Campylobacter species were found in high counts (6.58 $\log _{10}$ $\mathrm{CFU} / \mathrm{mL}$ ) in $50 \%$ of $\mathrm{FS}$ and CS against $16.67 \%$ of BS. The levels recorded for $C$. jejuni exceed USDA standards of $10.4 \%$ of contaminated raw chickens (WattAgNet, 2011). This contamination may be due to the coprophagic tendency of the birds (Newell and Fearnley, 2003) and the hot season (June-August).

\section{Slaughterhouse level}

Aerobic plate count started at $5.00 \log _{10}$ $\mathrm{CFU} / \mathrm{mL}$ and reached $9.5 \log _{10} \mathrm{CFU} / \mathrm{mL}$ after washing (Figure 2). Its lower number on farm and receiving area may be due to the limited area sampled by swabbing $\left(5 \times 5 \mathrm{~cm}^{2}\right)$, while the peak after washing may be attributed to cross-contamination between basins batches. Chilling reduced the number to $7.5 \log _{10}$ $\mathrm{CFU} / \mathrm{mL}$, but it was still above the international standards (5-7 $\log _{10} \mathrm{CFU} / \mathrm{g}$ ) reported by the International Commission on Microbiological Specifications for Foods (ICMSF,1986).

The increase of faecal coliforms between 
defeathering and evisceration (3.7 to $5.2 \log _{10}$ $\mathrm{CFU} / \mathrm{mL}$ ) supports the scenario of physical damage. Washing reduced them to $3.46 \log _{10}$ $\mathrm{CFU} / \mathrm{mL}$ and chilling to $2.00 \log _{10} \mathrm{CFU} / \mathrm{mL}$. However, ICMSF (1986) considered unnecessary to have microbiological criteria for these organisms because they are part of the natural flora of poultry. In the end product, $E$. coli was below $2 \log _{10} \mathrm{CFU} / \mathrm{mL}$ in $80 \%$ of carcasses rinsates, reaching the USDA standard. Following James et al. (2006), the water/immersion chilling reduces the number of indicator organisms by $1.1 \log _{10} \mathrm{CFU} / \mathrm{mL}$, without chlorine, and by $2.5 \log _{10} \mathrm{CFU} / \mathrm{mL}$ with chlorine. Cross-contamination in immersion chilling was also considered a major problem in the EU, hence the suggestion to use dry chilling.

Unlike for faecal coliforms, Campylobacters remained constant throughout the slaughtering chain $\left(5.95 \pm 0.04 \log _{10} \mathrm{CFU} / \mathrm{mL}\right)$. The slight increase after evisceration (5.88 to 5.97 $\log _{10}$ CFU/mL) may be due to contamination caused by rupture of viscera and/or due to bacterial self-protection mechanisms (Teh et al., 2010), where the formation of biofilm potentially enhances the survivability in poultry environment. This level of contamination is higher than $2.4 \log _{10} \mathrm{CFU} / \mathrm{mL}$ reported in carcasses (Chemaly et al., 2012).

Campylobacters were isolated from $95 \%$ of rinsates with the highest prevalence for $C$. jejuni (25\%), followed by $C$. lari (22\%), and $C$. coli (13\%). In spite of its fastidious nature, favourable conditions for the pathogenic $C$. jejuni were encountered along the processing line. As shown by other studies, poultry slaughterhouses were variably contaminated starting from $50 \%$ in the UK and $51.9 \%$ in Belgium (Habib et al., 2012) to $87.5 \%$ in French abattoirs (Hue et al., 2010). In this slaughterhouse, the constant levels of Campylobacters ( $\sim 6$ $\log _{10}$ CFU/mL) indicate that hygienic treatments were ineffective, keeping percentages above the acceptable 10.4\% USDA standard (WattAgNet, 2011). A systematic review showed an increase of Campylobacter by 10 to $72 \%$ after defeathering and by $15 \%$ after evisceration, while after washing results were inconsistent with a margin of $23 \%$ decrease to an increase of 13.3\% (Guerin et al., 2010).

Unlike $C$. coli and $C$. lari, $C$. jejuni showed a maximum after evisceration, to be reduced later by about $35 \%$. Campylobacters present in the intestines of slaughtered chickens would contaminate their carcasses throughout the processes. C. lari, absent at the reception, was detected after defeathering, while unidentified Campylobacters appeared to increase after washing.

Repeated rinsing of carcasses, designated as the vertical evolution (Figure 1) had no clear effect on Campylobacters. The lowest value recorded was after residual suction (5.73 $\log _{10} \mathrm{CFU} / \mathrm{mL}$ ) and the greatest after washing
(6.00 $\log _{10} \mathrm{CFU} / \mathrm{mL}$ ). Similar observations were recorded for horizontal and diagonal evolution.

\section{Dynamic index}

Dynamic index (DI) was calculated in relation to an arbitrary reference index equal to 100 at defeathering. The DI showed a positive increase throughout the process with the greatest value after refrigeration (Figure 3A). The cumulative DI reached 190.03 , which is equivalent to $1.43 \times 10^{6} \mathrm{CFU} / \mathrm{mL}$. Despite its sensitivity to environmental factors,
Campylobacter may have developed survival mechanisms such as the transition to a coccus shape, or through the development of a biofilm (Mihaljevic et al., 2007) adhering to the skin. The DI of $C$. jejuni (Figure 3B) decreased after evisceration $(-26.83 \%)$ and slightly after washing $(-4.03 \%)$. It increased by $20.37 \%$ after residual suction reaching its maximum of 40.24\% after refrigeration. Globally, C. jejuni increased by $29.75 \%$. The results showed that rearing and slaughtering conditions, mainly hygiene and chlorine treatment, were not adequate to render the end product safe.

\section{OPERATION}

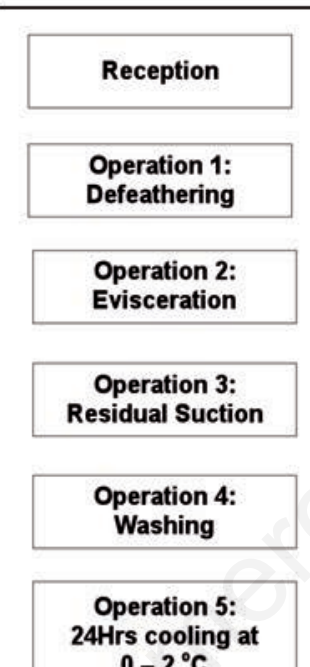
$0-2{ }^{\circ} \mathrm{C}$
SAMPLING TECHNIOUE
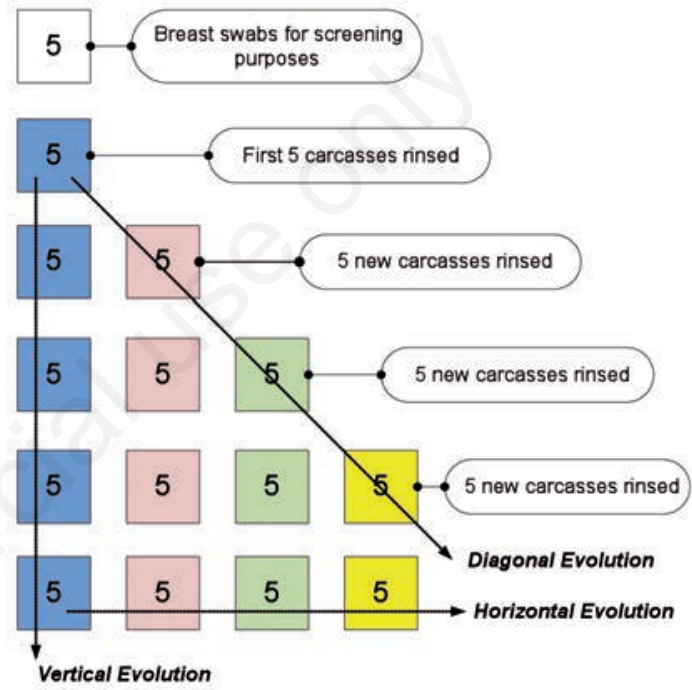

5

5

10

15

Figure 1. Sampling design for carcass rinsates showing the effect on the microbial load of frequent rinsing (vertical evolution), the number of rinsing (horizontal evolution) and no frequent rinsing (diagonal evolution).

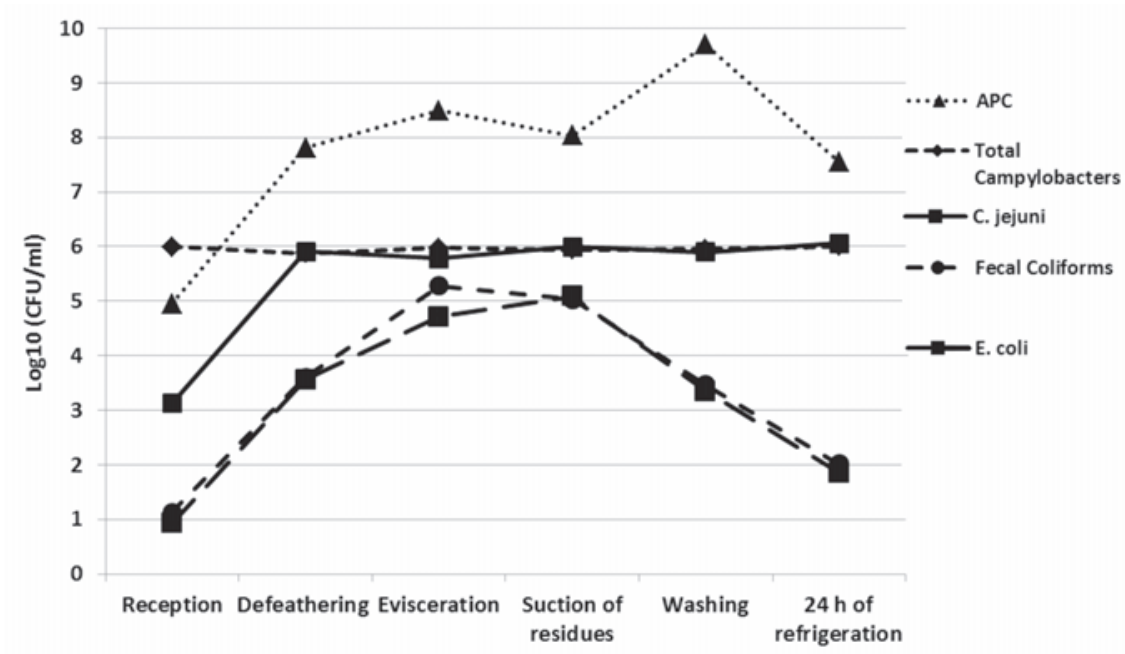

Figure 2. Dynamic of total Campylobacters, $C$. jejuni in comparison to aerobia plate counts, faecal coliforms and $E$. coli throughout the slaughtering operations. 

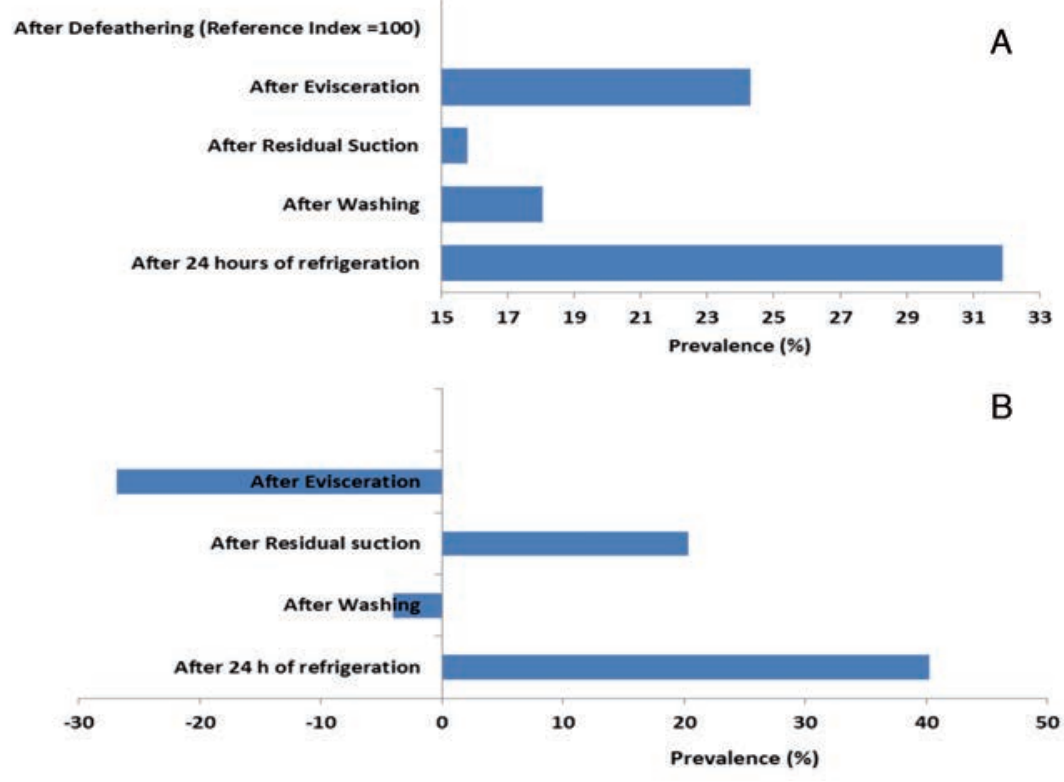

Figure 3. Dynamic index of Campylobacters (A) and Campylobacter jejuni (B) calculated relative to defeathering. Counts at defeathering: Campylobacters $=7.53 \times 10^{5} \mathrm{CFU} / \mathrm{mL} ; C$. jejuni $=8.2 \times 10^{5} \mathrm{CFU} / \mathrm{mL}$.

\section{Conclusions}

Sanitary practices and treatment conditions in the slaughterhouse tested in this study were effective against APC, faecal coliforms and $E$. coli only. Rearing system and slaughtering conditions were not able to reduce Campylobacters to an acceptable level. These last showed a high prevalence (95\%), with an almost constant count (6 $\left.\log _{10} \mathrm{CFU} / \mathrm{mL}\right)$ throughout the chain. Campylobacter jejuni dramatically increased after evisceration, before decreasing in the end product by $\approx 35 \%$. Since the final load of Campylobacter in the end product was higher than recommended standards and may pose potential risk to consumers, more effective measures and hygienic practices should be investigated.

\section{References}

Chemaly M, Magras C, Madec JY, Santolini J, Denis M, 2012. Campylobacter dans les filières de production animale. BEH HS 2012:17-9.

Dabboussi F, Alam S, Mallat H, Hlais S, Hamze M, 2012. Preliminary study on the prevalence of Campylobacter in childhood diarrhoea in north Lebanon. East Mediterr Health $\mathrm{J}$ 18:1225-8.

EFSA, 2011. Panel on biological hazards; scientific opinion on Campylobacter in broiler meat production: control options and performance objectives and/or targets at different stages of the food chain. EFSA J 9:1-141.
EFSA, 2013. The European Union Summary Report on trends and sources of zoonoses, zoonotic agents and food-borne outbreaks in 2011. EFSA J 11:3129.

Guerin MT, Sir C, Sargeant JM, Waddell L, O'Connor AM, Wills RW, Bailey RH, Byrd JA, 2010. The change in prevalence of Campylobacter on chicken carcasses during processing: a systematic review. Poultry Sci 89:1070-84.

Habib I, Berkvens D, De Zutter L, Dierick K, Van Huffel X, Speybroeck N, Geeraerd AH, Uyttendaele M, 2012. Campylobacter contamination in broiler carcasses and correlation with slaughterhouses operational hygiene inspection. Food Microbiol 29:105-12.

Hendriksen RS, Jaap Wagenaar, Van Bergen M, 2003. Global Salm-Surv. A global Salmonella surveillance and laboratory support project of the World Health Organization. Identification of thermotolerant Campylobacter. Available from: http:/www.antimicrobialresistance. dk/data/images/campylobacter4_pdf.pdf

Hue 0, Le Bouquin S, Laisney MJ, Allain V, Lalande F, Petetin I, Rouxel S, Quesne S, Gloaguen PY, Picherot M, Santolini J, Salvat J, Bougeard S, Chemaly M, 2010. Enquête sur la contamination de Campylobacter spp. des carcasses de poulets de chair en France en 2008 et les facteurs associés. Available from: http//www.formulaires.agriculture.gouv.fr/Bulletin-epidemiologique-no-41

ICMSF, 1986. Microorganisms in foods 2. Sampling for microbiological analysis: principles and specific applications. 2nd ed. International Commission on Microbiological Specifications for Foods - Blackwell Scientific
Publ., Hoboken, NJ, USA.

ISO, 2000. Water quality. Detection and enumeration of Escherichia coli and coliform bacteria. Part 1: membrane filtration method. ISO Norm 9308-1:2000. International Standardization Organization ed., Geneva, Switzerland.

ISO, 2003. Microbiology of food and animal feeding stuffs. Horizontal method for the enumeration of microorganisms. Colony-count technique at 30 degrees C. ISO Norm 4833:2003. International Standardization Organization ed., Geneva, Switzerland.

ISO, 2006a. Microbiology of food and animal feeding stuffs. Horizontal method for detection and enumeration of Campylobacter spp. Part 1: detection method. ISO Norm 10272-1:2006. International Standardization Organization ed., Geneva, Switzerland.

ISO, 2006b. Microbiology of food and animal feeding stuffs. Horizontal method for the enumeration of coliforms. Colony-count technique. ISO Norm 4832:2006. International Standardization Organization ed., Geneva, Switzerland

James C, Vincent C, Andrade Lima TI, James SJ, 2006. The primary chilling of poultry carcasses: a review. Int J Refrig 29:847-62.

Kudirkienė E, Bunevičienė J, Brǿndsted L, Ingmer H, Olsen JE, Malakauskas M, 2010. Evidence of broiler meat contamination with post-disinfection strains of Campylobacter jejuni from slaughterhouse. Int $\mathrm{J}$ Food Microbiol 145:116-20.

Marinou I, Bersimis S, Ioannidis A, Nicolaou C, Mitroussia-Ziouvia A, Legakis NJ, Chatzpanagiotou S, 2012. Identification and antimicrobial resistance of Campylobacter species isolated from animal sources. Front Microbiol 3:58.

Mihaljevic RR, Sikic M, Klancnik A, Brumini G, Mozina SS, Abram M, 2007. Environmental stress factors affecting survival and virulence of Campylobacter jejuni. Microb Pathogenesis 43:120-5.

Newell DG, Fearnley C, 2003. Sources of Campylobacter colonization in broiler chickens. Appl Environ Microb 69:4343-51.

Talhouk RS, El-Dana RA, Araj GF, Barbour E, Hashwa F, 1998. Prevalence, antimicrobial susceptibility and molecular characterization of Campylobacter isolates recovered from humans and poultry in Lebanon. J Med Liban 46:310-6.

Tam CC, 0’Brien SJ, Adak GK, Meakins SM, Frost JA, 2003. Campylobacter coli: an important foodborne pathogen. J Infection 47:28-32.

Teh KH, Flint S, French N, 2010. Biofilm formation by Campylobacter jejuni in controlled mixedmicrobial populations. Int J Food Micobiol 143:118-24.

WattAgNet, 2011. USDA announces new standards for reducing Salmonella and Campylobacter in chickens, turkeys. Available from: http//www.wattagnet. com/21220.html 